\title{
Task 6.5- Gas Separation and Hot-Gas Cleanup
}

\author{
Semi-Annual Report \\ January 1- June 30, 1996
}

\author{
By \\ Michael L. Swanson \\ Robert O. Ness, Jr. \\ John P. Hurley \\ Donald P. McCollor
}

Work Performed Under Contract No.: DE-FC21 -93 MC30097

For
U.S. Department of Energy
Office of Fossil Energy
Morgantown Energy Technology Center
P.O. Box 880
Morgantown, West Virginia 26507-0880

By

Energy and Environmental Research Center

University of North Dakota

P. O. Box 9018

Grand Forks, North Dakota 58202-9018 


\section{Disclaimer}

This report was prepared as an account of work sponsored by an agency of the United States Government. Neither the United States Government nor any agency thereof, nor any of their employees, makes any warranty, express or implied, or assumes any legal liability or responsibility for the accuracy, completeness, or usefulness of any information, apparatus, product, or process disclosed, or represents that its use would not infringe privately owned rights. Reference herein to any specific commercial product, process, or service by trade name, trademark, manufacturer, or otherwise does not necessarily constitute or imply its endorsement, recommendation, or favoring by the United States Government or any agency thereof. The views and opinions of authors expressed herein do not necessarily state or reflect those of the United States Govermment or any agency thereof, 


\section{DISCLAIMER}

This report was prepared as an account of work sponsored by an agency of the United States Government. Neither the United States Movement, nor any agency thereof, nor any of their employees makes any warranty, express or implied, or assumes any legal liability or responsibility for the accuracy, completeness, or usefulness of any information, apparatus, product, or process disclosed or represents that its use would not infringe privately owned rights. Reference herein to any specific commercial product, process, or service by trade name, trademark, manufacturer, or otherwise does not necessarily constitute or imply its endorsement, recommendation, or favoring by the United States Government or any agency thereof. The views and opinions of authors expressed herein do not necessarily y state or reflect those of the United States Government or any agency thereof.

\section{ACKNOWLEDGMENT}

This report was prepared with the support of the U.S. Department of Energy (DOE), Morgantown Energy Technology Center, Cooperative Agreement No.DE-FC21 -93 MC30097. However, any opinions, findings, conclusions, or recommendations expressed herein are those of the author(s) and do not necessarily reflect the views of the DOE.

\section{EERC DISCLAIMER}

LEGAL NOTICE This research report was prepared by the Energy \& Environmental Research Center (EERC), an agency of the University of North Dakota, as an account of work sponsored by U.S. Department of Energy, Because of the research nature of the work performed, neither the EERC nor any of its employees makes any warranty, express or implied, or assumes any legal liability or responsibility for the accuracy, completeness, or usefulness of any information, apparatus, product, or process disclosed, or represents that its use would not infringe privately owned rights. Reference herein to any specific commercial product, process, or service by trade name, trademark, manufacturer, or otherwise does not necessarily constitute or imply its endorsement or recommendation by the EERC. 


\section{TABLEOFCONTENTS}

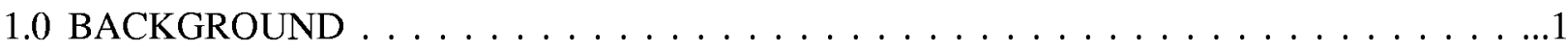

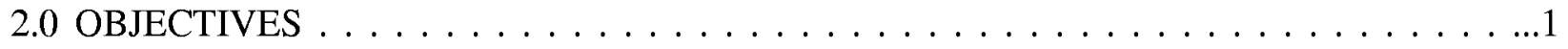

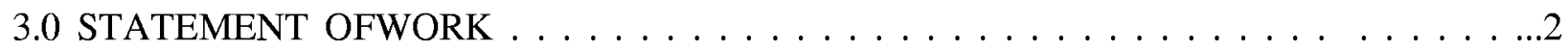

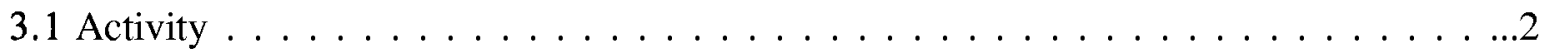

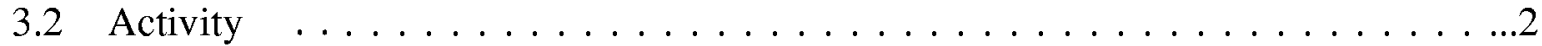

4.0 ACCOMPLISHMENTS . . . . . . . . . . . . . . . . . . . . . . 2

4.1 Literature Review ofMembrane Gas Separation Technology . . . . . . . . . . . 3

4.1 .1 Organic Membranes . . . . . . . . . . . . . . . ...3

4.1.2 Nonporous (Metal)Membranes . . . . . . . . . . . . . . ...3

4.1.3 Inorganic (Ceramic) Membranes . . . . . . . . . . . . . . . . ...3

4.1.4 Membrane Gas Separation . . . . . . . . . . . . . . . ...4

4.1.5 Transport inPorousMedia . . . . . . . . . . . . . . . . . ..4

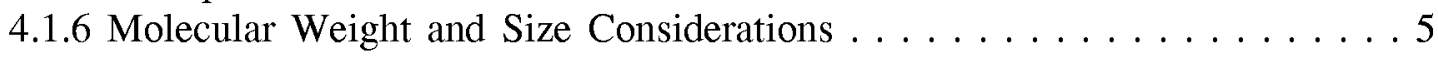

4.1 .7 Related Topics . . . . . . . . . . . . . . . . . . . ...6

4.1.7.1 Zeolite Hydrogen Encapsulation . . . . . . . . . . . . . . . ...6

4.1.7.2 Graphitic Layered Materials ... . . . . . . . . . . . . . . ..6

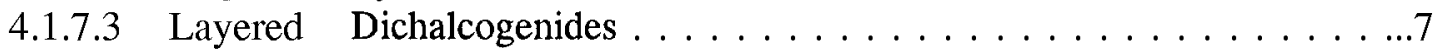

4.1.7.4 Active Membranes . . . . . . . . . . . . . . . . . . . . . . . ..7

4.1.7.5 Supported Liquid Membranes. . . . . . . . . . . . . . . . . ..8

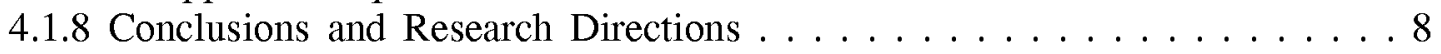

4.1.8.1 Summary of Membrane Technology Related To Hydrogen

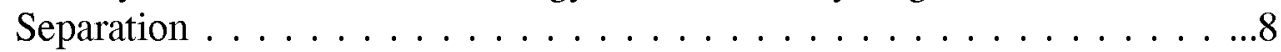

4.1.8.2 Research Directions .. . . . . . . . . . . . . . . . . . ...99

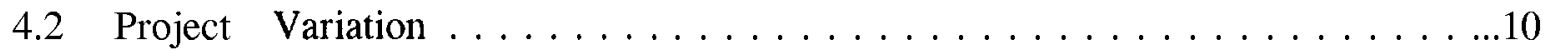

4.3 Transport Reactor Demonstration Unit Description . . . . . . . . . . . . . . 10

4.4 Pilot-Scale Hot-Gas Filter Vessel Description . . . . . . . . . . . . . . 12

4.5 Bend Research Gas Separation Membrane Accomplishments . . . . . . . . . . . 14

4.5.1 Equipment Description . . . . . . . . . . . . . . . . . 14

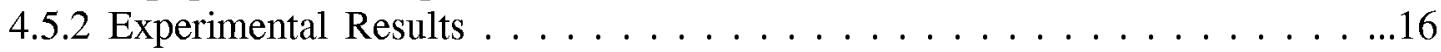

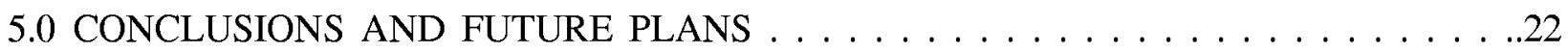

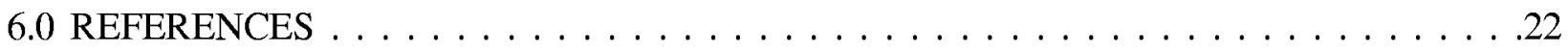




\section{LIST OF FIGURES}

1 TRDU with hot-gas filter vessel in the EERC gasification tower. . . . . . . . . 11

2 Schematic of hydrogen separation membrane test stand piping . . . . . . . . . 14

3 Photograph of hydrogen separation membrane test stand on TRDU . . . . . . . 15

\section{LIST OF TABLES}

1 Molecular Diameters $\ldots \ldots \ldots \ldots \ldots \ldots \ldots \ldots \ldots$

2 TRDU Operational Parameters . . . . . . . . . . . . . . . . . . . . . . 12

3 Design Criteria for the Pilot-Scale Hot-Gas Filter Vessel . . . . . . . . . . . . . . 13

4 Proximate and Ultimate Analysis of Belle Ayr Subbituminous Coal from the Powder River Basin Mixed with 5\% Plum Run Dolomite . . . . . . . . . . . . . . . 17

5 Operating Conditions from Product Gas Tests on Palladium-Copper Membrane . . . . . 17

6 Calculated Gas Composition Data from Bottled Gas Tests on Pd-Cu Membrane Assuming Permeate is Only Hydrogen . . . . . . . . . . . . . . . . . . . ...18

7 Gas Chromatograph Data from Coal Gas Tests on Pd-Cu Membrane Including Corrected Data from Raffinate and Permeate Gas Streams . . . . . . . . . . . . . . 18

8 Gas Chromatograph Data from Coal Gas Tests on $\mathrm{Pd}-\mathrm{Cu}$ Membrane . . . . . . . . . . 19

9 Gas Chromatograph Data from Bottled Gas Test on $\mathrm{Pd}-\mathrm{Cu}$ Membrane after Exposure to Coal-Derived Fuel Gas . . . . . . . . . . . . . . . . . . . ..21

10 Separation Factors and Permeabilities of Corrected Permeate Gases Through Pd-Cu

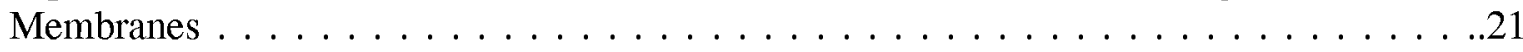




\section{TASK 6.5- GAS SEPARATION AND HOT-GAS CLEANUP}

\subsection{BACKGROUND}

Catalytic gasification of coal to produce $\mathrm{H}_{2}$ - and $\mathrm{CH}_{4}$-rich gases for consumption in molten carbonate fuelcells is currently under development; however, to optimize the fuel cell performance and extend its operating life, it is desired to separate as much of the inerts (i.e., $\mathrm{CO}_{2}$ and $\mathrm{N}_{2}$ ) and impurities (i.e., $\mathrm{H}_{2} \mathrm{~S}$ and $\mathrm{NH}_{3}$ ) as possible from the fuel gas before they enter the fuel cell. In addition, the economics of the integrated gasification combined cycle (IGCC) can be improved by separating as much of the hydrogen as possible from the fuel, since hydrogen is a high-value . product. One process currently under development by the Energy \& Environmental Research Center (EERC) for accomplishing this gas separation and hot-gas cleanup involves gas separation membranes. These membranes are operated at temperatures as high as $800^{\circ} \mathrm{C}$ and pressures up to $300 \mathrm{psig}$. Some of these membranes can have very small pores $(30-50 \AA)$, which inefficiently separate the undesired gases by operating in the Knudsen diffusion region of mass transport. Other membranes with smaller pore sizes $(<5 \AA)$ operate in the molecular sieving region of mass transport phenomena, Dissolution of atomic hydrogen into thin metallic membranes made of platinum and palladium alloys is also being developed.

Technological and economic issues that must be resolved before gas separation membranes are commercially viable include improved gas separation efficiency, membrane optimization, sealing of membranes in pressure vessels, high burst strength of the ceramic material, pore thermal stability, and material chemical stability. Hydrogen separation is dependent on the temperature, pressure, pressure ratio across the membrane, and ratio of permeate flow to total flow. For gas separation under Knudsen diffusion, increasing feed pressure and pressure ratio across the membrane should increase gas permeability; decreasing the temperature and the permeate-to-total flow ratio should also increase gas permeability. In the molecular sieving regime of mass transport, the inlet pressure and pressure ratio should have no effect on gas permeability, while increasing temperature should increase permeability.

\subsection{OBJECTIVES}

The objective of Subtask 6.5 is to develop and test superior gas separation membranes. Several methods are to be tested to prepare new membrane materials, including physical vapor deposition via electron beam evaporation. The selectivity of these membrane materials for separating undesired gases was to be determined. Selectivity will be measured by feeding the gases to the membrane and sampling the inlet, permeate, and raffinate streams for gas composition and volumetric flow rate.

Specific questions to be answered during the year include the following:

. What are the effects of ceramic membrane properties (i. e., surface area, pore size, coating thickness) on permeability and selectivity of the desired gases? 
-What are the effects of operating conditions (i. e., temperature, pressure, and flow rate) on permeability and selectivity?

\subsection{STATEMENT OF WORK}

\subsection{Activity 1}

Several methods for preparing a membrane material, including physical vapor deposition via electron beam evaporation, are to be tested, Other ceramic filter materials utilized in hot-gas particulate filters will be obtained from selected suppliers as substrates to develop a thin-film membrane selective to hydrogen permeation. This thin-film membrane will be prepared by a modified EERC proprietary process. The base 'filter materials will already have been characterized for hydrothermal and chemical stability and pore size.

\subsection{Activity 2}

A bench-scale (4-lb/hr) continuous fluid-bed reactor is available to test bottled gas mixtures or to provide an actual coal-derived fuel gas stream for the testing of selected membranes. A Foxboro 93 1C process gas chromatography or a HP 5880 gas chromatography will be utilized to determine gas composition of all gas streams.

\subsection{ACCOMPLISHMENTS}

A literature review was completed to gain an overview of the current state of the art in membrane technology and materials, as well as to examine potential membrane materials for hydrogen separation applications. The highlights of a previous literature search covering membrane preparation methods were also incorporated. The review is presented below.

The review suggested that the most likely chance for a successful high-temperature membrane for hydrogen separation from a gasification product stream would be a ceramic analog of a dense metal membrane, where the hydrogen would dissolve into and diffuse through the membrane structure. An oxygen-deficient aluminosilicate membrane or a variant thereof appears promising, since an n-type semiconductor character is favorable for the chemisorption of $\mathrm{H}_{2}$. The membrane layer would likely have to be very thin for appreciable amounts of hydrogen to diffuse through it.

Work on development of a thin-film membrane was previously delayed by the departure of a key person and the absence of a suitable replacement, as well as delays in project funding. A person has now been assigned to the project. Electrical and water utilities have been installed for the electron-beam coating machine, and the coater is near operating condition. Preliminary tests to produce membrane coatings are expected to began in July. 


\subsection{Literature Review of Membrane Gas Separation Technology}

A significant amount ofresearch hasbeen undertaken worldw idein thedevelopment of rnembranesforgas separations, This review is an overview of the current state of the art in membrane technology and materials, and an examination of potential membrane materials for hydrogen separation applications, rather than an exhaustive literature search. The highlights of the previous literature search covering membrane preparation methods are also incorporated.

Membrane materials that have been investigated in the literature include organic membranes, carbon (graphitic and pyrolized), inorganic materials, metal oxides, and metals such as palladium and alloys thereof. In addition, hybrid combinations such as metals deposited on porous inorganic substrates have been tested. To date, only the organic and metal membranes have achieved significant commercialization, with a more limited use of carbon and ceramic membranes.

\subsubsection{Organic Membranes}

Organic membranes have achieved success as a result of the ability to closely engineer and control membrane structure at the molecular level, the capacity for almost infinite modification of membrane properties via membrane chemistry modifications, and the capability to economically produce uniform membrane materials in quantity. Very small (angstrom-scale) porosity is achievable. The principal drawback to the use of organic membranes is the relatively low operating temperature (typically $70^{\circ} \mathrm{C}$ ) (1). This precludes organic membranes from consideration for hydrogen separation from hot gasifier process gas streams, although some of the separation methodology may find analogies for other membrane materials.

\subsubsection{Nonporous (Metal) Membranes}

Dense (nonporous) membranes for hydrogen separations have been confined to metals, although other inorganic materials are conceivable. Metal membrane use has been focused primarily on the separation and production of high-purity hydrogen, It has long been known that palladium, platinum, gold, and silver absorb significant quantities of hydrogen, as well as to a lesser extent do nickel, iron, and other transition metals (2). The process can be considered a dissolution of the hydrogen into the metal lattice. When a gradient of partial pressure exists across a thin, for example, palladium, membrane hydrogen is selectively transported through the membrane. Although the permeability is rather low, very high-purity hydrogen is obtained. These metal membrane materials are capable of withstanding high temperatures (typically $\left.800^{\circ} \mathrm{C}\right)(3)$, allowing use in hot process gas streams. Work on metal membrane separations has been performed primarily in the former Soviet Union, with some commercialization. The principal drawback to the use of metal membranes is cost, with the additional problems of embrittlement from thermal cycling and poisoning by other components in the process gas stream. Some research success has been attained at reducing cost, embrittlement, and poisoning by depositing thin metal films on or in porous inorganic substrates (4).

\subsubsection{Inorganic (Ceramic) Membranes}

Inorganic membranes for gas separation are primarily in the research stage, although pyrolized carbon and graphitic membranes have found some commercial application (5). Current 
preparation technique consists of selecting a suitable microporous inorganic substrate to provide necessary membrane strength. The achievable substrate pore diameters currently commercially available are greater than 30-40 $\AA$. A thin inorganic coating on and/or in the pores is then applied, sealing the "large" substrate pores, and providing a supported ultrathin permeable membrane. Commonly used coating methods that have been employed are slip casting a sol-gel onto the substrate, chemical vapor deposition of reacting gases, and electron beam coating. Other processes include formation of a thin oxide coating by electrochemical anodization of metal films and pyrolysis of organic compounds sorbed into the substrate. The inorganic membranes have been shown to possess good resistance to corrosive atmospheres, as well as the ability to withstand high temperatures, As yet, technical problems of fragility and sealing remain. The principal barrier, however, is the rather low permeability and selectivity of the inorganic membranes, particularly for hydrogen separations. The following sections discuss the inherent difficulties of gas separations due to membrane structure in greater detail.

\subsubsection{Membrane Gas Separation}

Fundamental limitations are set on gas separation even by an ideal membrane. A gas permeable to the membrane will diffuse across it until the partial pressure is equal on either side, even though the total gas pressure may be substantially greater on one side. It is this difference in partial pressure that drives the diffusion.

Practical considerations introduce further complications. As an example, palladium is highly selective to hydrogen, approximating an ideal membrane. To achieve the maximum separation, the process gas stream (of which hydrogen is a fractional part) would be maintained at the highest possible inlet pressure, while pure hydrogen is removed (pumped away) from the other side to maintain the lowest possible outlet pressure. Since the product hydrogen pressure cannot practically be reduced to zero, and there is an upper limit to the gas pressure on the process side, it follows that it is not possible to completely remove hydrogen from the process stream. Further, the palladium membrane must be mechanically robust enough to withstand the total differential gas pressure, i.e., relatively thick. However, the rate of hydrogen diffusion decreases with increasing membrane thickness, "slowing the separation process while increasing the cost of the membrane. The "break-even" point for unsupported palladium alloy membranes used for hydrogen separation is approximately $0.04 \mathrm{~mm}$ for hydrogen production from natural gas, above which other technologies such as pressure-swing absorption are more cost-effective (6). Thus the interest in metal thin films mounted on inexpensive porous substrates.

\subsubsection{Transport in Porous Media}

Four principal transport mechanisms are useful for the membrane separation of gas mixtures: Knudson diffusion, surface diffusion, capillary condensation, and size exclusion (molecular sieving). Knudson diffusion is effective with pore diameters of 50-500 $\AA$, with separation limited by the square root of the molecular weights of the gasses. Surface diffusion occurs when one component is preferentially absorbed on the membrane surface, therefore having a locally higher concentration and increased diffusion. This becomes significant at pore diameters of 10-100 Capillary condensation occurs under certain conditions when gases will condense in the pores of the membrane. If other gases do not dissolve in the liquid phase, their diffusion is blocked and only the condensed gas diffuses through the membrane. Molecular sieving is based on the extremely 
small pore diameters (3- $10 \AA$ ) for which larger gas molecules are physically too big to enter and diffuse through $(7,8)$.

\subsubsection{Molecular Weight and Size Considerations}

Separation of hydrogen from a gas mixture by Knudson diffusion depends on the ratio of the square roots of the molecular weights. This places an upper theoretical limit on the degree of separation possible. The Knudson model was developed for binary gas mixtures, and loses somewhat of its meaning with a multiple-gas mixture. However, the degree of hydrogen separation is at most a modest 5:1 for the gases in a typical gasifier product stream, This is too low to be economical for most applications (9). Separation performance can be improved by staging membranes in series, the most notable example being the separation of U-235 from U-238 (as gaseous $\mathrm{UF}_{6}$ - "the most practical or rather the least inconvenient volatile compound of uranium" [7], relative separation 1.0043). The process requires at least 1000 membrane stages to enrich to $3 \%$ U-235, with accompanying massive physical facilities and cost (7).

The Knudson model assumes the diameter of the gas molecules is insignificant in relation to the pore diameters. Thus, there is a transition region where molecular size becomes significant relative to pore size, but pore diameter is still too large for molecular sieving to occur. In this region, separation factors actually decrease relative to the Knudson separation factors $(9,10)$. Other effects, i.e., surface diffusion and capillary condensation, may enter into the separation factor. As an example, Ohya et al., examining silica-zirconia and silica-borate composite membranes with pore diameters of $10-30 \AA$, reported no hydrogen permeation in the presence of gaseous water or hydrogen bromide $(11,12)$. This was apparently due to capillary condensation of the water and/or hydrogen bromide in the membrane pores.

Molecular sieving occurs when some components of a gas mixture are physically too large to enter the membrane pores. This results in extremely high separation factors, with the diffusion of the "too big" gas molecules effectively zero. The phenomenon is commonly seen in the use of zeolites for gas separations by pressure-swing absorption and as catalyst supports. For hydrogen separation, pore diameter is critical because of the small difference in molecular size of the components of a gasifier product stream, Table 1 gives calculated molecular sizes for common gasifier product components $(9,13)$.

TABLE 1

Molecular Diameters. $\AA$

\begin{tabular}{ll}
\hline $\mathrm{H}_{2}$ & 2.97 \\
$\mathrm{CH}_{4}$ & 3.88 \\
$\mathrm{H}_{2} \mathrm{O}$ & 2.82 \\
$\mathrm{CO}$ & 3.59 \\
$\mathrm{~N}_{2}$ & $3.70 *$ \\
$\mathrm{H}_{2} \mathrm{~S}$ & 3.73 \\
$\mathrm{CO}_{2}$ & 4.00 \\
\hline
\end{tabular}

* Interpolated from Reference 13 . 
It should be noted that no account of molecular shape is included in the average diameters given, All of the species listed should have a smaller "endways" than "crossways" projected area. Further, there is range of only $1.03 \AA$ between the smallest (hydrogen) and largest (carbon dioxide) gas molecule listed. This places extremely severe restrictions on the pore size diameter and range of pore sizes for hydrogen separation by molecular sieving.

\subsubsection{Related Topics}

Several related research topics are of interest to the development of a membrane for hydrogen separation. There has been research with zeolites applicable to the molecular sieving approach, properties of graphitic and inorganic layered materials, research with supported liquid membranes and active membranes applicable to the "capillary condensation" separation approach.

\subsubsection{Zeolite Hydrogen Encapsulation}

Zeolites are extremely porous aluminosilicate materials with a regular crystalline arrangement of pores in the 4-12 $\AA$ range. They are used extensively for molecular sieving of aqueous and organic liquids, ion-exchange processes, gas separation by pressure-swing absorption, and as catalyst supports. The pore size and the ability to be custom-synthesized and ion-exchanged to exhibit specific molecular sieve properties make zeolites a potential membrane material for hydrogen separation.

A reference in a study of $\mathrm{Kr}-85$ storage in zeolites (14) noted that hydrogen could be reversibly encapsulated in certain zeolites. This was of significance because it indicated that at least some pores in the zeolite cage structure were very close to the molecular dimension of hydrogen gas. Research by Fraenkel et al. (15-19), has demonstrated that hydrogen enters the cage structure of Cs-exchanged $\mathrm{Na}-\mathrm{A}$ zeolite at $2000-4000 \mathrm{C}$ and zeolites containing up to $1 \%$ by weight $\mathrm{H}_{2}$ were stable at ambient temperature. The hydrogen is released again by reheating the zeolite back to $200^{\circ}-400^{\circ} \mathrm{C}$. The encapsulation was explained as a combination of $\mathrm{H}_{2}$ trapped in six-ring member pore diameter beta cages and in eight-ring member alpha cages partially blocked by cesium ions. Conclusions of later work using a variety of zeolites have disputed this explanation and indicate that water enters the same pores as the hydrogen molecules (20). This would be the expected result based on the molecular diameters of Table 1 . The process of preparing a variety of thin zeolite films on a porous inorganic substrate by a slip form method has been patented (21). No specific examples of application of cations or of tailoring zeolites specifically for hydrogen separation were given. It should be noted that zeolite preparation is not well documented and is as much an art as a science (22).

\subsubsection{Graphitic Layered Materials}

Graphitic carbon exists as layered sheets of joined six-membered carbon rings ("chicken wire"), with the layers loosely held together by weak bonding forces, The layer separation is

$3.4 \AA$, in the range of interest for molecular sieving. Graphite is relatively chemically inert and has been long known to intercalated a number of gas molecules and inorganic cations between the carbon layers. The intercalation of other compounds with graphite has been quite extensively studied (23). A major obstacle to the possible use of a graphitic molecular sieve is the swelling behavior exhibited on intercalation. This is due to an increase in the carbon layer separation as guest 
molecules occupy sites between layers. The swelling indicates that a graphitic membrane would not be highly selective for a gasifier product stream, as well as being potentially unstable structurally.

Some examination of carbon molecular sieves has been done, both as a zeolite replacement for pressure-swing absorption (24) and with hollow fiber carbon gas separation membranes (5). The latter was formed by the pyrolysis of an organic polymer, forming a carbonized hollow fiber with microporous walls. The diffusion mechanism appears to be through pores rather than via intercalation. These carbonized polymers exhibited similar or better selectivity than polymer membranes with permeability 1 to 2 orders of magnitude greater. Experiments with the fiber and a $\mathrm{H}_{2}-\mathrm{CH}_{4}$ gas mixture indicated that the $\mathrm{CH}_{4}$ does not affect $\mathrm{H}_{2}$ permeability. The carbon fibers were relatively easy to produce, but rather brittle.

\subsubsection{Layered Dichalcogenides}

Dichalcogenides are crystalline compounds of formula $\mathrm{MX}_{2}$, where $\mathrm{M}$ is a divalent metal and $\mathrm{X}$ is $\mathrm{S}$ or Se. They are noncarbon inorganic analogues of graphite, with similar layers weakly held together by weak bonding forces and interlayer separations. Interest in these materials is relatively recent, with the bulk of the research directed at synthesis and fundamental chemical and physical properties, Little was mentioned about thermal or chemical stability. The dichalcogenides do intercalated small molecules in the same manner as graphite (13).

One study was found dealing with the intercalation of hydrogen in a transition metal dichalcogenide $\left(\mathrm{NbSe}_{2}\right)$ to evaluate suitability for hydrogen storage (25). Hydrogen introduced into the $\mathrm{NbSe}_{2}$ at $350^{\circ} \mathrm{C}$ would remain in the material and be rereleased on heat to $300^{\circ} \mathrm{C}$. The research dealt only with the $\mathrm{NbSe}_{2}-\mathrm{H}_{2}$ system, and no mention was made of interaction or chemical stability to other gases. These materials are in the research stage, with little or no actual application as yet.

\subsubsection{Active Membranes}

As stated previously, a fundamental limitation of gas separation by a membrane is that the process cannot remove the gas of interest from the feed stream to a partial pressure less than that of the gas on the product side. This applies only to a passive membrane with the transport occurring by diffusion processes. With an active membrane, the gas can be "pumped" against the partial pressure gradient by application of an external energy source. The process is basically an electrochemical cell.

Such a membrane has been developed for hydrogen transport by Energy Research Corporation (26). The system is a supported liquid membrane, basically a phosphoric acid fuel cell "operating in reverse". Testing indicated a $90 \%$ recovery of $99 \%$ purity hydrogen from a $10 \%$ hydrogen feed stream, and was tolerant of $\mathrm{H}_{2} \mathrm{~S}$. However, the liquid electrolyte is contained by porous organic membranes with a temperature limit of $200^{\circ} \mathrm{C}$. Analogous inorganic membranes practical at high temperatures are zirconium oxide and certain perovskite active membranes, which are specific for oxygen transport (27). The use of an active membrane for hydrogen purification would be of interest if an inorganic membrane specific to hydrogen transport could be found. 


\subsubsection{Supported Liquid Membranes}

The derivative of the phosphoric acid fuel cell (26) is an example of a supported liquid membrane. Previously, the phenomenon of capillary condensation was noted and the strong, albeit unintentional, effect on gas diffusion and membrane selectivity when gases such as water condense in membrane pores. Deliberate flooding of the pores of a commercial organic membrane with silicone, fluorocarbon, and mineral oils gave an enhanced permeability to oxygen over nitrogen, due to the higher volubility of oxygen in the oils. A similar high selectivity and flux for carbon dioxide was found with water-filled membranes because of the significant volubility of $\mathrm{CO}_{2}$ in water (8). To date, no attempt at producing a high-temperature liquid membrane appears to have been made.

\subsubsection{Conclusions and Research Directions}

\subsubsection{Summary of Membrane Technology Related To Hydrogen Separation}

Organic Membranes

- Technology is mature.

- Good separations are possible.

. Temperature limitations make organic membranes unsuitable.

Metal Membranes

- Technology is mature.

- Good resistance to temperature.

- Problems with strength, fatigue, poisoning,

- Cost is a major problem.

Ceramic Membranes (Knudson diffusion)

- Technology is in the research stage.

- Good resistance to temperature, corrosive atmospheres.

- Problems with reproducibility, fragility, surface cracking.

-Pure Knudson diffusion is unsuitable for separation.

Ceramic Membranes (molecular sieve)

- Technology is in the early research stage.

- Good resistance to temperature, corrosive atmosphere.

- Problems with fabrication, stability.

- Separations rely on very small size differences.

Graphitic Membranes

- Technology is in the research/commercial stage.

- Good resistance to temperature, atmospheres.

- Problems with fragility, probable problems with swelling.

- Current] y relying on pores; may not be highly selective.

Dichalcogenide Membranes

- Technology is in the early research stage. 
-Uncertainties as to robustness, selectivity, temperature resistance.

. Probably not as highly selective as graphites.

Active Ceramic Membranes

- No reference found for Hz-selectivity,

- Potential good resistance to temperature, atmospheres,

- Potential high selectivity.

- No examples are known.

Supported Liquid (ceramic) Membranes

- No reference found for high-temperature applications.

- Potential good resistance to temperature, atmosphere.

- Potential problems with stability, performance degradation.

- No examples are known.

\subsubsection{Research Directions}

The most likely successful high-temperature membrane for hydrogen separation from a gasification product stream would appear to be a ceramic analog of a dense metal membrane, where the hydrogen would dissolve into and diffuse through the membrane structure. An oxygendeficient aluminosilicate membrane or a variant thereof appears to be sound, since an n-type semiconductor such as $\mathrm{ZnO}$ is favorable for the chemisorption of $\mathrm{H}_{2}(28)$. The membrane layer would likely have to be very thin for appreciable amounts of hydrogen to diffuse through.

Less likely to succeed is a supported liquid ceramic membrane. In concept, a microporous (pore diameter $10-40 \AA$ ) ceramic substrate would have the pores flooded with a second ceramic material that 1) becomes liquid at the membrane operating temperature, 2) is immiscible with the solid substrate phase, and 3) has an affinity for hydrogen and/or in which hydrogen has a high volubility. No such membrane appears to have yet been proposed and may not be possible.

Also less likely to succeed is the zeolite-type molecular sieve membrane. A sodalite-type structure appears to have the best chance, with the pore size approaching that needed for passing only hydrogen, Uncertainties exist in the approach to fabrication, the selectivity and diffusion rate, and the stability. Other aluminosilicate materials may be suitable if the lattice structure expands on heating to operating temperature to approach the $2.97 \AA \mathrm{H}_{2}$ diameter. Again the membrane itself would likely have to be very thin.

The active ceramic membrane that is hydrogen-selective is unlikely to be successful. The concept is attractive, but there appears to be no such material known and no likely starting point to searching for one.

Layered materials, such as graphite, appear unlikely to succeed because of the swelling behavior and nonselectivity of intercalation.

Ceramic membranes employing Knudson diffusion are unlikely to succeed because of low separation factors, unless a means can be found to significantly enhance the surface diffusion of hydrogen or to discourage the other gas components. 
Dense metal membranes are at a commercial stage, with the known problems being cost and engineering issues rather than any technical obstacles.

\subsection{Project Variation}

To get back on schedule during the first year, the scope of work was changed to test a gas separation membrane provided by another vendor. Bend Research, Inc., has a new membrane material that could be tested on the transport reactor demonstration unit (TRDU). The TRDU was scheduled to operate at the end of 1995 in support of hot-gas filter testing under a separate U.S. Department of Energy (DOE) -funded project. The membrane module was to be tested at minimal cost on a slipstream of product gas from the filter vessel outlet for a 200 -hour period to test membrane performance and durability. The membrane module is the same module that was tested here last year; only the membrane material is different. This material is much less sensitive to the presence of $\mathrm{H}_{2} \mathrm{~S}$ than the previous membrane tested. Variables to be tested include hydrogen concentration, hydrogen sulfide concentration, membrane temperature, and gas flow rate through the membrane. The effect of these variables on the membrane performance (hydrogen permeability and selectivity) will be determined as a function of time.

\subsection{Transport Reactor Demonstration Unit Description}

The following is a short description of the TRDU fluidized-bed gasifier located at the EERC. The TRDU system can be divided into three sections: the coal feed section, the TRDU, and the product recovery section. The TRDU proper, as shown in Figure 1, consists of a riser reactor with an expanded mixing zone at the bottom, a disengage, and a primary cyclone and standpipe. The standpipe is connected to the mixing section of the riser by a J-leg transfer line. All of the components in the system are refractory-lined and designed mechanically for $150 \mathrm{psig}$ and an internal temperature of $1090 \mathrm{oC}(2000 \mathrm{oF})$. Table 2 provides the operational parameters for the unit.

The premixed coal and limestone feed to the transport reactor can be admitted through three nozzles which are at varying elevations. Oxidant is fed to the reactor through two pairs of nozzles at varying elevations within the mixing zone. For the combustion mode of operation, additional nozzles are provided in the riser for feeding secondary air. Hot solids from the standpipe are circulated into the mixing zone, where they come into contact with the oxidant and the steam, which is injected into the J-leg. This feature enables spent char to contact oxidant and steam prior to the fresh coal feed. This staged gasification process enhances process efficiency. Gasification or combustion and desulfurization reactions are carried out in the riser as coal, sorbent, and oxidant (with steam for gasification) flow up the tube. The solids circulation into the mixing zone is controlled by the solids level in the standpipe. The bulk of entrained solids leaving the riser is separated from the gas stream in the disengage and circulated back to the riser via the standpipe. Gas exiting the disengage enters a cyclone. Gas exiting this cyclone enters a jacketed pipe heat exchanger and then goes either through a pilot-scale hot-gas filter vessel or directly into a sieve tower, two water venturi scrubbers, and finally the flare. Solids from the dipleg of the cyclone flow into the standpipe and are removed through a lock hopper. A solids stream is withdrawn from the standpipe via an auger to maintain the system's solids inventory. 


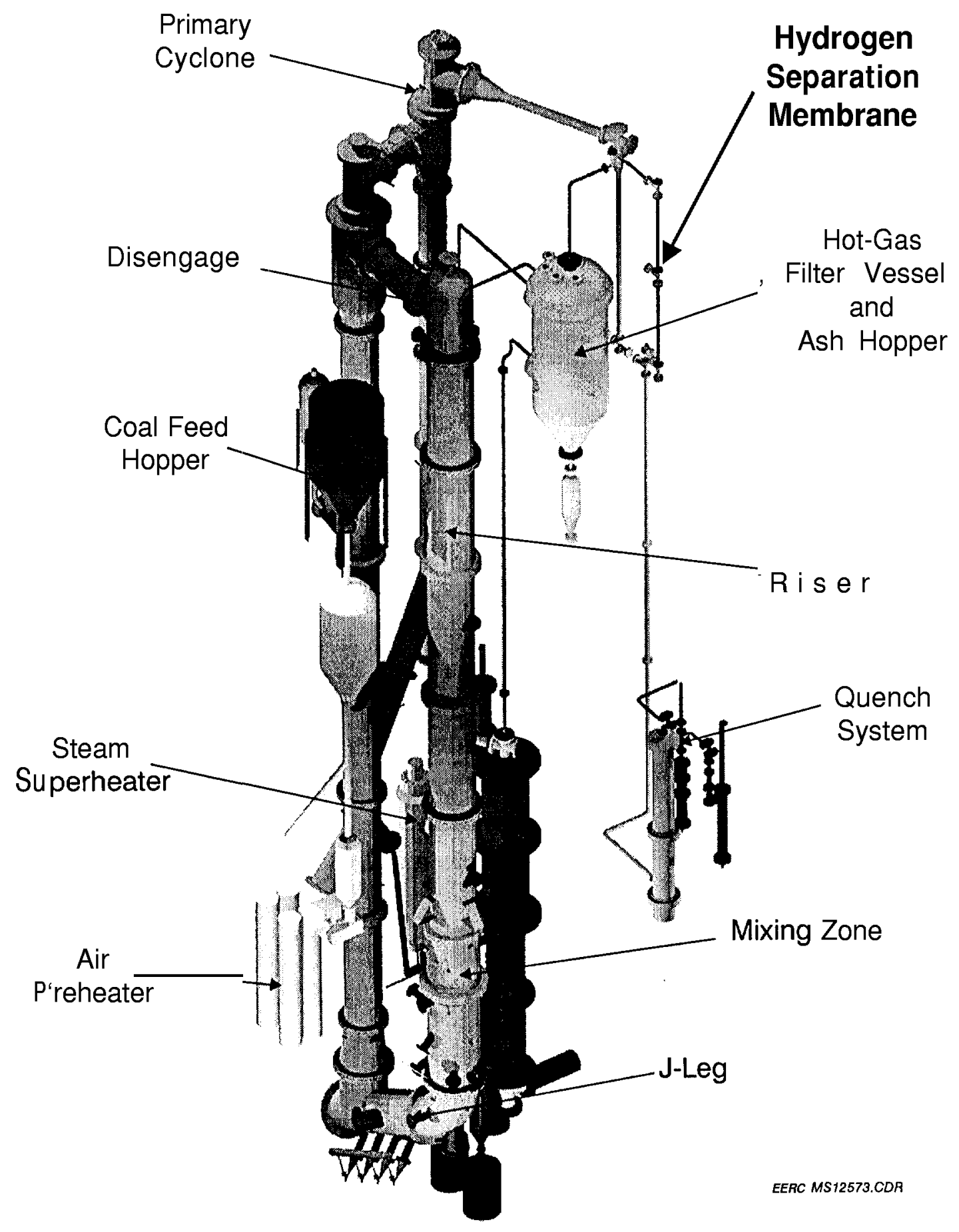

Figure 1. TRDU with hot-gas filter vessel in the EERC gasification tower. 
TABLE 2

TRDU Operational Parameters

\begin{tabular}{|c|c|}
\hline Parameter & $\begin{array}{c}\text { Actual } \\
\text { Operating } \\
\text { Condition } \\
\end{array}$ \\
\hline Coal & Wyodak \\
\hline Moisture Content, \% & 20 \\
\hline Pressure, psig & $117-122$ \\
\hline Steam:Coal Ratio & 0.38 \\
\hline Air:Coal Ratio & $3.5-4.7$ \\
\hline Ca:S Ratio, mole & 1.5 \\
\hline Air Inlet Temperature, oC & 425 \\
\hline Steam Preheat, oC & 390 \\
\hline Coal Feed Rate, lb/hr & 173 \\
\hline Gasifier Temperature, maximum oC & 850 \\
\hline AT, maximum oC & 121 \\
\hline Conversion, $\%$ & 96 \\
\hline HHV of Fuel Gas, Btu/scf & 104 \\
\hline Heat Loss as Coal Feed, \% & 27 \\
\hline Riser Velocity, $\mathrm{ft} / \mathrm{s}$ & $28-30$ \\
\hline Heat Loss, Btu/hr & $420,000^{2}$ \\
\hline Standpipe Superficial Velocity, ft/s & $0.4-0.54$ \\
\hline
\end{tabular}

${ }^{1}$ Steady-state conditions were not achieved.

${ }^{2}$ Estimated heat loss; steady-state conditions were not achieved.

\subsection{Pilot-Scale Hot-Gas Filter Vessel Description}

A new hot-gas filter vessel (HGFV) program was started in March 1995 as an addition to the Morgantown Energy Technology Center (METC) Cooperative Agreement entitled Subtask 3.13Hot-Gas Filter Testing. This new subtask has also supported upgrades to the TRDU and is anticipated to support as many as three 200-hour filter tests in the next 21 months. First-year funding was made available in March 1995 and has supported upgrades to the TRDU, installation of the new filter vessel, and new inlet/outlet piping requirements and will support one 200-hour filter test, as initiated on this subtask during the first quarter of 1995. The preliminary filter design criteria are summarized in Table 3. 
TABLE 3

Design Criteria for the Pilot-Scale Hot-Gas Filter Vessel

\begin{tabular}{lc}
\hline Range of Operating Conditions & $1000-1800 \mathrm{oF}$ \\
\hline Inlet Gas Temperature & $120-150 \mathrm{psi}$ \\
Operating Pressure & $325 \mathrm{scfm}$ \\
Volumetric Gas Flow & up to 19 \\
Number of Candles & $4 \mathrm{in.} \mathbf{\mathbb { L }}$ to $\mathbb{\Phi}$ \\
Candle Spacing & $2.5-10 \mathrm{ft} / \mathrm{min}$ \\
Filter Face Velocity & $1000-5000 \mathrm{ppm}$ \\
Particulate Loading & $<50^{\circ} \mathrm{F}$ \\
Temperature Drop Across HGFV & Unheated \\
\hline
\end{tabular}

This vessel (also shown in Figure 1) is designed to handle all of the gas flow from the TRDU at its expected operating conditions. The vessel is approximately 48 in. inside diameter (ID) and $185 \mathrm{in}$. long and would be designed to handle gas flows of approximately 300 to $325 \mathrm{scfm}$ at temperatures up to $1800^{\circ} \mathrm{F}$ and pressures of $130 \mathrm{psig}$. The refractory has a 28 -in. ID with a shroud diameter of $22 \mathrm{in}$. The vessel is sized to handle candle filters up to 1.5 meters long; however, 1meter candles are being utilized in the initial $1000^{\circ} \mathrm{F}$ gasification tests. Candle filters are 2.375 in. outside diamter and have a 4 -in. center line-to-center line spacing. The total number of 1-meter candles mounted in the current geometry of the HGFV tube sheet is 19 . Since the first series of gasification tests are to be completed in the $1000^{\circ}-1200^{\circ} \mathrm{F}$ range, a length of concentric pipe heat exchanger is utilized to drop the gas temperature to the desired range. By inserting an existing set of high-temperature valves in the fuel gas heat exchanger, it is possible to bypass the filter vessel during start-up and shakedown of the TRDU and switch to the preheated filter vessel when steadystate conditions are achieved. This number of filters enables filter face velocities as low as 2.5 $\mathrm{ft} / \mathrm{min}$ to be tested. Higher face velocities would be achieved in future tests by using fewer candles.

Ports have been added in the filter vessel to allow temperature and pressure measurements to be obtained and to insert a water-cooled borescope probe for inspecting candle filters. The ash letdown system consists of two sets of alternating high-temperature valves with a conical pressure vessel that acts as a lock hopper.

The nitrogen backpulse system is constructed to backpulse up to four sets of five candle filters in a time-controlled sequence. The pulse length and volume of nitrogen displaced into the filter vessel are controlled by the regulated pressure (up to $800 \mathrm{psig}$ ) of the nitrogen reservoir and the solenoid valves used to control the timing of the gas pulse. 


\subsection{Bend Research Gas Separation Membrane Accomplishments}

\subsubsection{Equipment Description}

A test stand has been constructed for testing a slipstream of the TRDU product gas through the Bend Research membrane module. Figure 2 is a schematic showing the process piping used to install the membrane on the TRDU, This diagram shows that a temperature switch was installed on the permeate outlet so that in the event of a membrane rupture, a downstream actuated ball valve would shut to prevent the uncontrolled discharge of the TRDU fuel gas through the permeate gas line, This test stand was built to allow additional hydrogen and nitrogen to be injected into the slipstream, which will permit different gas compositions to be tested. After passing through the heated membrane, the raffinate gas passes through glycol-cooled quench pots to condense moisture and organics, then through the backpressure valve used to control the slipstream flow rate. The low-pressure hydrogen-rich permeate stream passes through a water-cooled tube-and-shell heat exchanger before passing through a product gas meter, Sample gases are collected on the inletraffinate and permeate gas streams for analysis by gas chromatography-with the monitored flow rates allowing for calculation of hydrogen separation efficiencies. Figure 3 is a photograph of the test stand located on the TRDU hot-gas filter exit piping. The test sequence allows the effect of coal gasifier product gas impurities (such as $\mathrm{H}_{2} \mathrm{~S}, \mathrm{HC}$, etc.) to be determined. It was decided to run most of the tests at a hydrogen partial pressure of 50 psia.

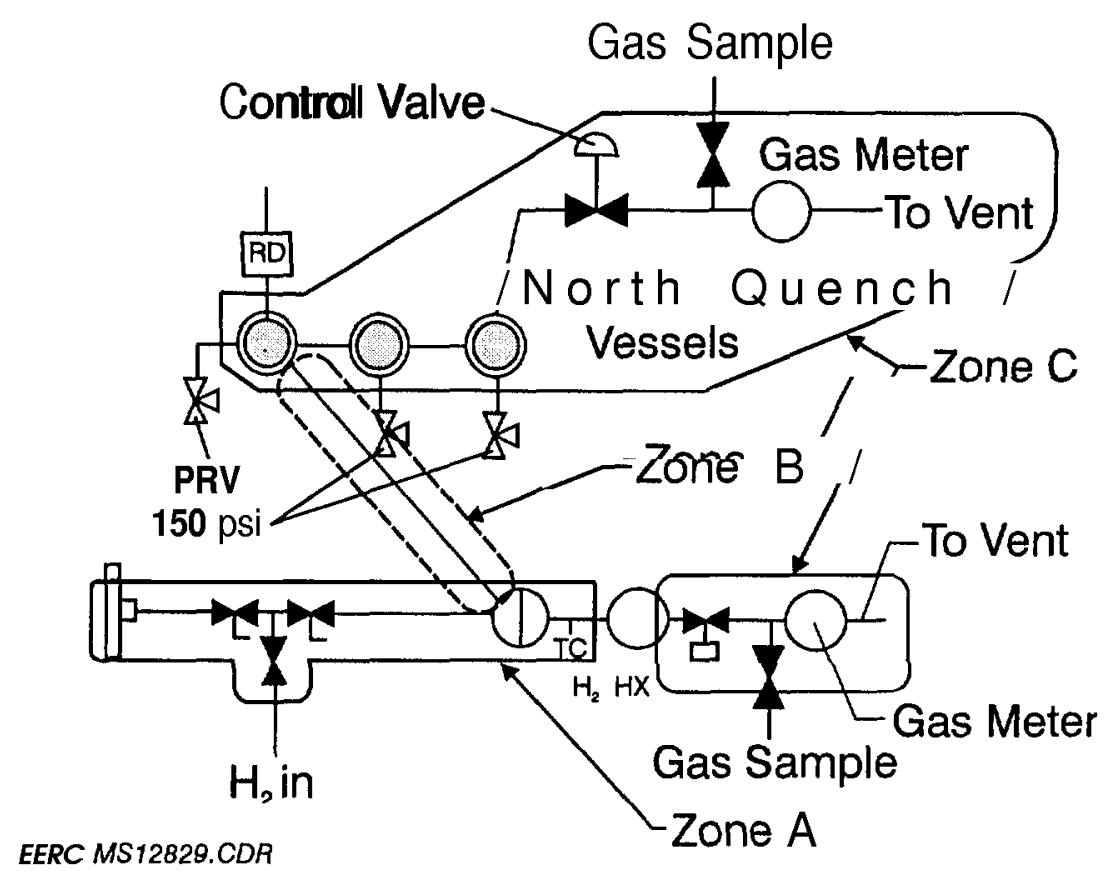

Figure 2. Schematic of hydrogen separation membrane testing stand piping. 


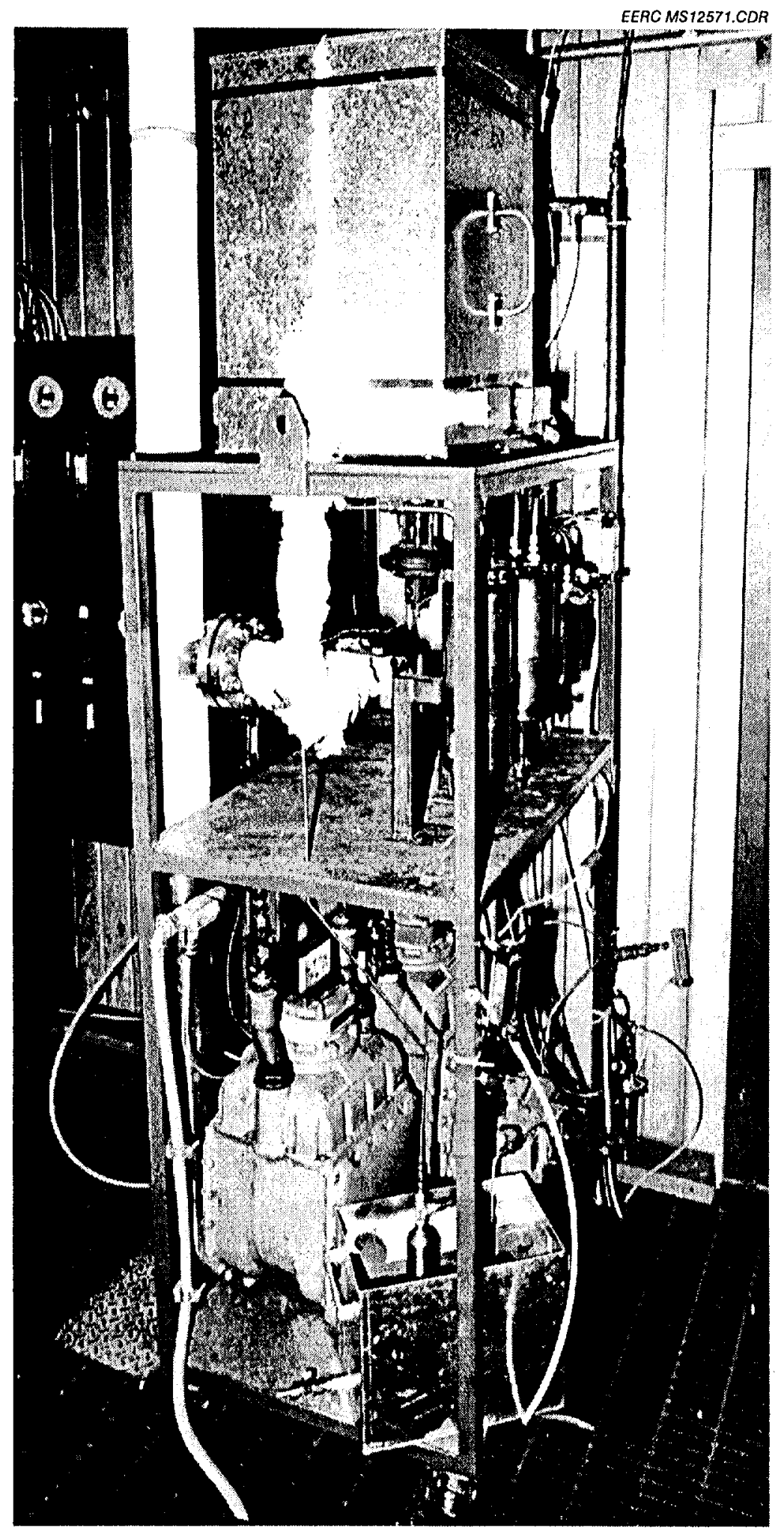

Figure 3. Photograph of hydrogen separation membrane test stand on TRDU. 
All gas analysis was performed using a Hewlett-Packard 5880 gas chromatography equipped with a refinery gas analysis package. The refinery gas analysis package provides an analysis equivalent to that specified by Universal Oil Products (UOP) Method 539-73. The gas chromatography used thermal conductivity detectors and employs two carrier gas streams. Hydrogen and helium are separated and determined in an argon carrier gas stream. In an argon carrier gas, the response for hydrogen is linear over the entire concentration range from $\mathrm{O} \%$ to $100 \%$ hydrogen. The rest of the gas components are separated and determined in a high-purity helium carrier gas stream. The instrument is calibrated daily with Certified-Grade standard gas mixtures. The minimum detection limit (MDL) for the refinery gas analyzer package is 0.01 mole\%, except for $\mathrm{CO}_{2}, \mathrm{CO}, \mathrm{N}_{2}, \mathrm{O}_{2}, \mathrm{CH}_{4}$, and $\mathrm{H}_{2} \mathrm{~S}$, which all have a MDL of 0.02 mole\%.

The gas composition of the coal-derived gas stream was adjusted by adding some bottled hydrogen gas to the gas stream entering the reactor. Table 4 shows the proximate and ultimate analysis of the $16 \times 60$-mesh coal-dolomite used to provide the coal-derived fuel gas for the testing of the membranes. W yodak subbituminous coal from the Powder River Basin was selected because its low sulfur and ash levels should allow lower $\mathrm{H}_{2} \mathrm{~S}$ levels. In order to reduce the $\mathrm{H}_{2} \mathrm{~S}$ levels further, 5\% Plum Run dolomite was added to the fuel to capture as much of the sulfur as possible in the bed.

\subsubsection{Experimental Results}

Table 5 shows the operating conditions at which the bottled and coal gas tests were performed on the palldium-copper membrane. A total of 83 hours of exposure to bottled gas with no $\mathrm{H}_{2} \mathrm{~S}$ present and an additional 50 hours of exposure to coal gas with approximately $300 \mathrm{ppm}$ of $\mathrm{H}_{2} \mathrm{~S}$ was achieved. While coal gas from the TRDU is being used, a gasifier upset such as a coal feed plug or a circulation loss due to the blowover of the bed material could result in the presence of $\mathrm{O}_{2}$ in the fuel gas because of insufficient fuel in the mixing zone of the gasifier to consume all of the incoming air. Thus several times during the test, the hydrogen stream to the membrane would be turned off during a process upset to prevent the presence of $\mathrm{O}_{2}$ and $\mathrm{H}_{2}$ in the membrane at the same time. This limited the time during which the membrane was at steady-state conditions; however, four reasonably long steady-state periods on coal gas were identified, along with five bottle gas steady- state operating periods.

Tables 6-9 show the gas analysis of the feed gas, raffinate, and permeate streams taken for these tests. This table also shows corrected gas analyses for the raffinate and permeate gas streams after correction for some dilution effects that would result from a small quantity of air being present in the sampling lines used to fill the gas bags. This correction assumed that no $\mathrm{O}_{2}$ should be present in the gas samples and normalized the $0_{2}$ and a corresponding amount of $\mathrm{N}_{2}$ (in a $21 \%$ to $79 \%$ ratio) from the gas bag concentrations. 
TABLE 4

Proximate and Ultimate Analysis of Belle Ayr Subbituminous Coal from the Powder River Basin Mixed with 5\% Plum Run Dolomite

\begin{tabular}{llll}
\hline Wyodak Subbituminous & $\mathrm{A}$ & $\mathrm{s}-\mathrm{R} \mathrm{u} \mathrm{n}$ & Moisture-free \\
\hline Proximate Analysis & & \\
Moisture & 23.3 & $\mathrm{NA}^{*}$ \\
Volatile Matter & 37.7 & 49.1 \\
Fixed Carbon & 31.9 & 41.6 \\
Ash & 7.1 & 9.3 \\
Ultimate Analysis & & \\
Hydrogen & 6.29 & 4.83 \\
Carbon & 50.46 & 65.81 \\
Nitrogen & 0.77 & 1.00 \\
Sulfur & 0.32 & 0,42 \\
Oxygen (Ind.) & 35.06 & 18.68 \\
Ash & 7.10 & 9.26 \\
Heating Value (Btu/lb) & 8,778 & 11,445 \\
\hline
\end{tabular}

* Not applicable.

TABLE 5

Operating Conditions from Product Gas Tests on Palladium-Copper Membrane

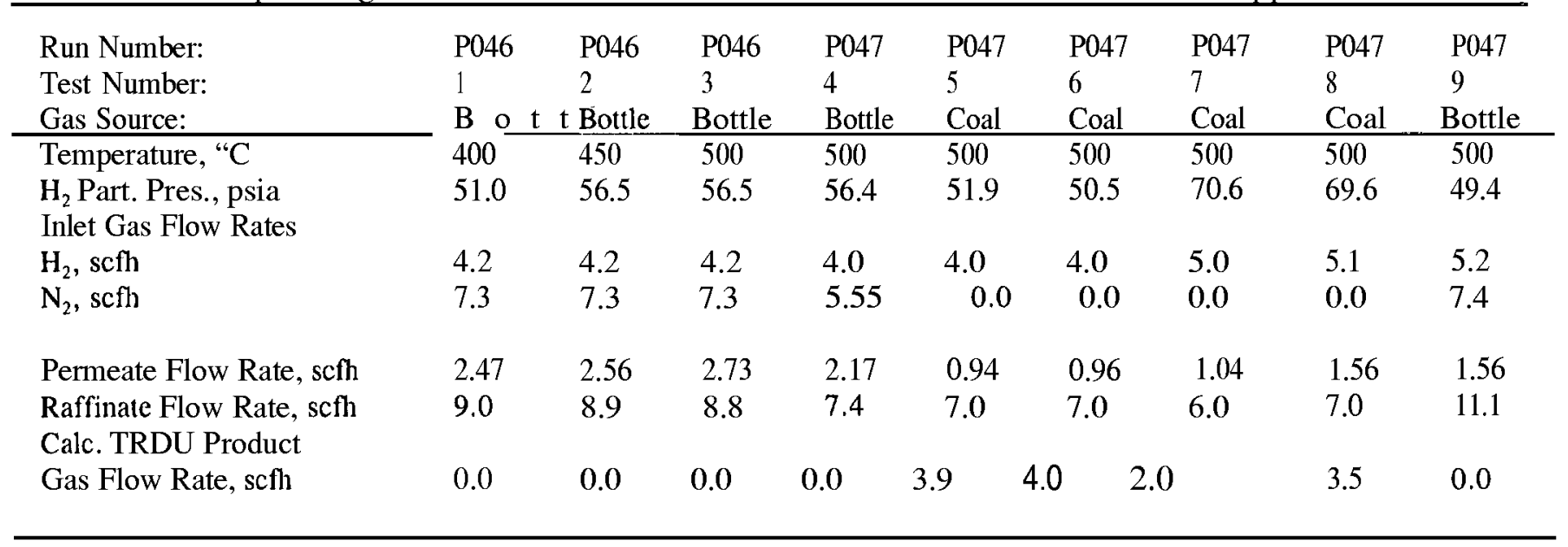


Calculated Gas Composition Data from Bottled Gas Tests on Pd-Cu Membrane Assuming Permeate is Only Hydrogen

\begin{tabular}{|c|c|c|c|c|c|c|c|c|c|c|c|c|}
\hline Run Number: & $\mathrm{P} 046$ & P046 & P046 & $\mathrm{P} 046$ & $\mathrm{P} 046$ & $\mathrm{P} 046$ & P046 & P046 & P046 & $\mathrm{P} 047$ & P047 & $\mathrm{P} 047$ \\
\hline Test Number: & 1 & 1 & 1 & 2 & 2 & 2 & 3 & 3 & 3 & 4 & 4 & 4 \\
\hline Sample Type: & Feed & Raf. & Perm. & Feed & Raf. & Perm. & Feed & Raf. & Perm. & Feed & Raf. & Per \\
\hline \multicolumn{13}{|c|}{ Gas Composition, mol\% } \\
\hline $\mathrm{H}_{2}$ & 36.5 & 19.1 & 100 & 36.5 & 18.3 & 100 & 36.5 & 16.7 & 100 & 41.9 & 24.8 & 100 \\
\hline $\mathrm{N}_{2}$ & 63.5 & 80.9 & & 63.5 & 81.7 & & 63.5 & 83.3 & & 58.1 & 75.2 & \\
\hline Total & 100 & 100 & 100 & 100 & 100 & 100 & 100 & 100 & 100 & 100 & 100 & 100 \\
\hline
\end{tabular}

\section{TABLE 7}

Gas Chromatography Data from Coal Gas Tests on Pd-Cu Membrane Including Corrected Data from Raffinate and Permeate Gas Streams

\begin{tabular}{|c|c|c|c|c|c|c|c|c|c|c|c|}
\hline $\begin{array}{l}\text { Run Number: } \\
\text { Test Number: } \\
\text { Sample Type: }\end{array}$ & $\begin{array}{l}\text { Avg. } \\
\text { Prod. }\end{array}$ & $\begin{array}{c}\mathrm{P} 047 \\
5 \\
\text { Calc. } \\
\text { Feed } \\
\end{array}$ & $\begin{array}{c}\mathrm{P} 047 \\
5 \\
\\
\text { Raf. }\end{array}$ & $\begin{array}{c}\text { P047 } \\
5 \\
\text { Cor. } \\
\text { Raf. }\end{array}$ & $\begin{array}{c}\text { P047 } \\
5 \\
\text { Perm. }\end{array}$ & $\begin{array}{c}\text { P047 } \\
5 \\
\text { Cor. } \\
\text { Perm. } \\
\end{array}$ & $\begin{array}{c}\mathrm{P} 047 \\
6 \\
\text { Calc. } \\
\text { Feed } \\
\end{array}$ & $\begin{array}{c}\text { P047 } \\
6 \\
\text { Raf. }\end{array}$ & $\begin{array}{c}\text { P047 } \\
6 \\
\text { Cor. } \\
\text { Raf. } \\
\end{array}$ & $\begin{array}{c}\text { P047 } \\
6 \\
\\
\text { Perm. }\end{array}$ & $\begin{array}{c}\text { P047 } \\
6 \\
\text { Cor. } \\
\text { Perm. }\end{array}$ \\
\hline \multicolumn{12}{|c|}{ Gas Composition, mol\% } \\
\hline $\mathrm{H}_{2}$ & 5.3 & 43.4 & 33.9 & 35.8 & 90.1 & 99.9 & 42.2 & 30.6 & 34.2 & 99.2 & 99.9 \\
\hline $\mathrm{N}_{2}$ & 77.1 & 47.7 & 55.5 & 54.1 & 8.0 & & 47.3 & 56,9 & 53.7 & 0.65 & 0.03 \\
\hline $\mathrm{CO}_{2}$ & 11.5 & 7.0 & 7.6 & 8.0 & & & 7.4 & 7.5 & 8.4 & & \\
\hline $\mathrm{co}$ & 4.4 & 1.6 & 1.7 & 1.8 & & & 2.6 & 2.6 & 3.0 & & \\
\hline $\mathrm{CH}_{4}$ & 0.86 & 0.3 & 0.31 & 0.32 & & & 0.49 & 0.50 & 0.56 & & \\
\hline $\mathrm{C}_{2} \mathrm{H}_{4}$ & 0.08 & 0.03 & 0.03 & 0.03 & 0.05 & 0.06 & 0.05 & 0,06 & 0.03 & & \\
\hline $\mathrm{He}$ & 0.04 & 0.04 & 0.02 & 0.02 & 0.02 & 0.02 & 0.04 & 0,04 & 0.06 & 0.03 & 0.03 \\
\hline $\mathrm{H}_{2} \mathrm{~S}$ & 0.05 & 0.03 & 0.03 & 0.03 & & & 0.03 & 0,03 & 0.04 & & \\
\hline OJAr & 0.64 & & 0.9 & & 1.8 & & & 1,87 & & 0.13 & \\
\hline Total & 100 & 100.1 & 100 & 100.1 & 100 & 100 & 100 & 100 & 100 & 100 & 100 \\
\hline
\end{tabular}


TABLE 8

Gas Chromatograph Data from Coal Gas Tests on Pd-Cu Membrane

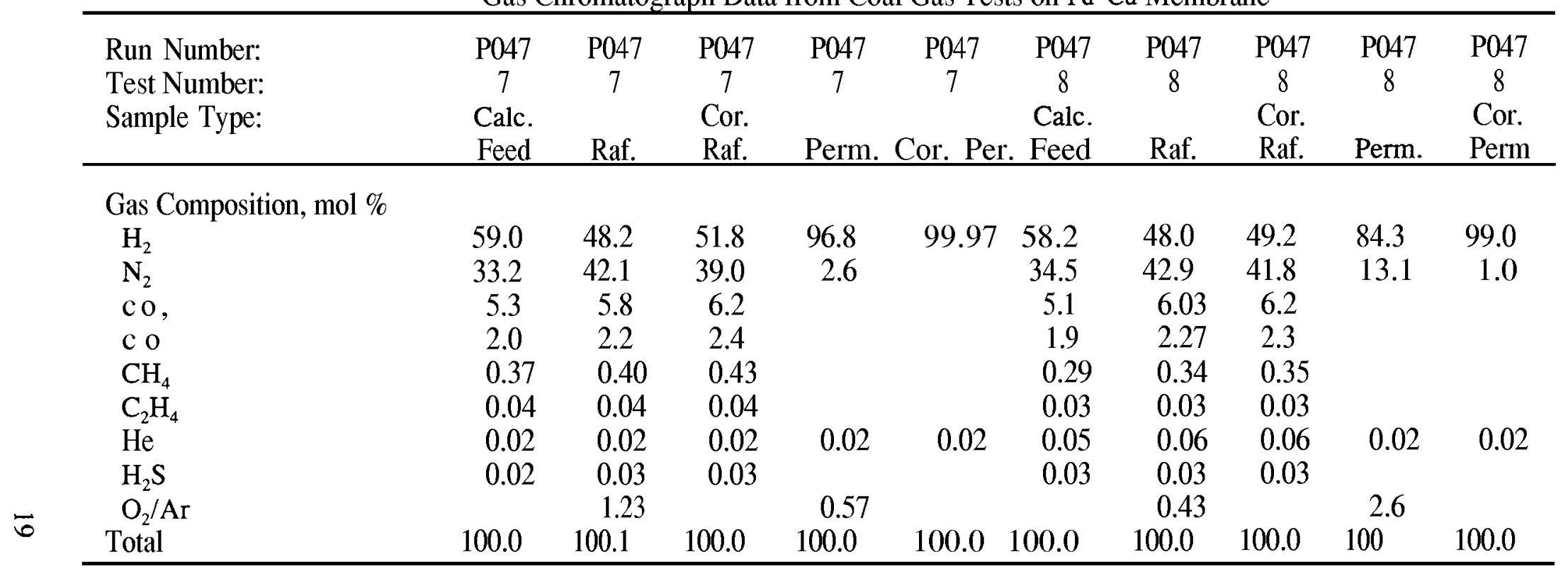


A common measure of a membrane performance is its separation factor, which is defined in the following equation as:

$$
\alpha_{\mathrm{ij}}=\frac{Y_{\mathrm{i}} L X_{\mathrm{i}}}{Y_{\mathrm{j}} / X_{j}}
$$

where $\alpha_{\mathrm{ij}}=$ separation factor (dimensionless)

$Y_{\mathrm{i}}=$ mole fraction of component $\mathrm{I}$ in permeate

$Y_{j}=$ mole fraction of component $j$ in permeate

$\mathrm{Xi}=$ mole fraction of component $\mathrm{I}$ in feed

$X_{j}=$ mole fraction of component $\mathrm{j}$ in feed

Separation factors for these product gas tests on the Bend Research, Inc., membranes are shown in Table 10. The permeability results have been reported as a permeate gas flow rate per unit transrnembrane pressure per unit membrane surface area (i.e.,scfh/psid $\mathrm{H}_{2} / \mathrm{ft}^{2}$ ). These results are also displayed in Table 10.

These number indicate that higher separation factors can be achieved with these membranes than with ceramic membranes, since the permeabilities of the undesired gases are very low. However, the permeability of hydrogen gas is also much lower than those reported for ceramic membranes (29).

Comparing the calculated hydrogen permeabilities with those determined from previous tests performed using $\mathrm{Pd}-\mathrm{Ag}$ and $\mathrm{Pd}$ membranes (30), it is apparent that the hydrogen permeability for the $\mathrm{Pd}-\mathrm{Cu}$ membrane $\left(0.33 \mathrm{scfh} / \mathrm{psid} / \mathrm{ft}^{2}\right)$ is lower than that for the $\mathrm{Pd}-\mathrm{Ag}$ membrane $\left(\mathrm{O} .43 \mathrm{scfh} / \mathrm{psid} / \mathrm{ft}^{2}\right)$ with no $\mathrm{H}_{2} \mathrm{~S}$ present. However, when $\mathrm{H}_{2} \mathrm{~S}$ was present in the product gas at $10 \mathrm{ppm}$, the hydrogen permeability of the Pd-Ag membrane would fall off to 0.03 $\mathrm{scfh} / \mathrm{psid} / \mathrm{ft}^{2}$, and at higher levels approaching $200 \mathrm{ppm}, \mathrm{Pd}-\mathrm{Ag}$ membrane permeability fell to zero. However, with the $\mathrm{Pd}-\mathrm{Cu}$ membrane at $300 \mathrm{ppm}$, the hydrogen permeability fell to approximately $0.14 \mathrm{scfh} / \mathrm{psid} / \mathrm{ft}^{2}$. Thus, the $\mathrm{Pd}-\mathrm{Cu}$ membrane is not as detrimentally affected by the presence of $\mathrm{H}_{2} \mathrm{~S}$ as is the $\mathrm{Pd}-\mathrm{Ag}$ membrane. The $\mathrm{Pd}-\mathrm{Cu}$ membrane seemed to continue to operate at $40 \%$ to $50 \%$ of its original capacity in the presence of $\mathrm{H}_{2} \mathrm{~S}$ up to $300 \mathrm{ppm}$. The hydrogen permeabilities again indicate how sensitive the palladium-based membranes are to hydrogen sulfide in the feed gas. Permeability also appears to be significantly affected by membrane temperature. The total quantity of hydrogen passing through the membrane is affected by the hydrogen partial pressure, but hydrogen permeability is not. 
TABLE 9

Gas Chromatography Data from Bottled Gas Test on Pd-Cu Membrane after Exposure to Coal-Derived Fuel Gas

\begin{tabular}{lrrrrc}
\hline Run Number: & P047 & P047 & P047 & P047 & P047 \\
Test Number: & 9 & 9 & 9 & 9 & 9 \\
Sample Type: & Calc. & & Cor. & & $\begin{array}{c}\text { Cor. } \\
\text { Perm. }\end{array}$ \\
& Feed & Raf. & Raf. & Perm. & \\
\hline Gas Composition, mol \% & & & & & \\
$\mathrm{H}_{2}$ & 37.9 & 29.1 & 29.2 & 99.26 & 99.8 \\
$\mathrm{~N}_{2}$ & 62.1 & 70.8 & 70.8 & 0.64 & 0.21 \\
$\mathrm{O}_{2} / \mathrm{Ar}$ & & 0.04 & & 0.09 & 0.01 \\
$\mathrm{He}$ & 0.03 & 0.03 & 0.03 & 0.01 & 100 \\
Total & 100 & 100 & 100 & 100 & \\
\hline
\end{tabular}

TABLE 10

Separation Factors and Permeabilities of Corrected Permeate Gases Through Pd-Cu Membranes

\begin{tabular}{|c|c|c|c|c|c|c|c|c|c|}
\hline $\begin{array}{l}\text { Run Number: } \\
\text { Test Number: }\end{array}$ & $\begin{array}{l}\text { P046 } \\
\mathrm{I}\end{array}$ & $\begin{array}{l}\mathrm{P} 046 \\
2\end{array}$ & $\begin{array}{l}\mathrm{P} 046 \\
3 \\
\end{array}$ & $\begin{array}{l}\mathrm{P} 047 \\
4 \\
\end{array}$ & $\begin{array}{l}\mathrm{P} 047 \\
5 \\
\end{array}$ & $\begin{array}{l}\mathrm{P} 047 \\
6 \\
\end{array}$ & $\begin{array}{l}\mathrm{P} 047 \\
7 \\
\end{array}$ & $\begin{array}{l}\mathrm{P} 047 \\
8 \\
\end{array}$ & $\begin{array}{l}\mathrm{P} 047 \\
9\end{array}$ \\
\hline \multicolumn{10}{|l|}{ Separation Factor } \\
\hline $\mathrm{H}_{2}$ to $\mathrm{N}_{2}$ & $\infty$ & $\mathrm{m}$ & $\infty$ & $\infty$ & $\mathrm{m}$ & 3593 & $\infty$ & 59 & 667 \\
\hline $\mathrm{H}_{2}$ to $\mathrm{CO}_{2}$ & $\infty$ & $\infty$ & $\infty$ & $\infty$ & $\infty$ & $\infty$ & $\infty$ & $\infty$ & $\infty$ \\
\hline $\mathrm{H}_{2}$ to $\mathrm{CO}$ & $\infty$ & $\infty$ & $\mathrm{m}$ & $\infty$ & $\infty$ & $\infty$ & $\infty$ & $\infty$ & $\infty$ \\
\hline $\mathrm{H}_{2}$ Permeability & & & & & & & & & \\
\hline $\mathrm{scfh} / \mathrm{psid} \mathrm{H}_{2} / \mathrm{ft}^{2}$ & 0.34 & 0.31 & 0.33 & 0.26 & 0.13 & 0.13 & 0.09 & 0.14 & 0.19 \\
\hline H, Recovery, \% & 59 & 61 & 65 & 54 & 27 & 29 & 25 & 31 & 31 \\
\hline
\end{tabular}




\subsection{CONCLUSIONS AND FUTURE PLANS}

A total of 83 hours of membrane exposure to bottled gas with no $\mathrm{H}_{2} \mathrm{~S}$ present, with an additional 50 hours of exposure to coal gas with approximately $300 \mathrm{ppm}$ of $\mathrm{H}_{2} \mathrm{~S}$ was achieved. Comparing the calculated hydrogen permeabilities with those determined from previous tests performed using Pd-Ag and $\mathrm{Pd}$ membranes (2), it is apparent that the hydrogen permeability for the $\mathrm{Pd}-\mathrm{Cu}$ membrane is lower than that for the $\mathrm{Pd}-\mathrm{Ag}$ membrane with no $\mathrm{H}_{2} \mathrm{~S}$ present . However, when $\mathrm{H}_{2} \mathrm{~S}$ was present in the product gas, the hydrogen permeability of the $\mathrm{Pd}-\mathrm{Ag}$ membrane would fall off to zero at the $\mathrm{H}_{2} \mathrm{~S}$ levels seen in the TRDU gasification test, while the Pd-Cu membrane seemed to still operate at $40 \%$ to $50 \%$ of its original capacity in the presence of up to $300 \mathrm{ppm}$ of $\mathrm{H}_{2} \mathrm{~S}$. Thus, the Pd-Cu membrane is not detrimentally affected by the presence of $\mathrm{H}_{2} \mathrm{~S}$ as the Pd-Ag membrane; however the change in hydrogen permeabilities indicate how sensitive the palladium-based membranes are to $\mathrm{H}_{2} \mathrm{~S}$ contamination. Permeability also appears to be significantly affected by membrane temperature. The total quantity of hydrogen passing through the membrane is affected by the hydrogen partial pressure, but hydrogen permeability is not. These data indicate that higher separation factors can be achieved with these membranes than with ceramic membranes, since the permeabilities of the undesired gases are very low. However, the permeability of hydrogen gas is also much lower than that of ceramic membranes.

The most likely ceramic membrane for future testing of high-temperature hydrogen separation from a gasification product stream has been targeted as a ceramic analog of a densemetal membrane, where the hydrogen would dissolve into and diffuse through the membrane structure. An oxygen-deficient amorphous membrane such as an aluminosilicate or other material appears to be promising. Preliminary tests to produce membrane coatings are expected to began in July.

\subsection{REFERENCES}

1. Poku, J. A.; Plunkett, J.E. "Gas Separation Applications to METC-Supported Technologies," final report DOE/MC/21353-2793 (DE90000440); Dec. 1989.

2. Sneed, M. Cannon; Brasted, Robert C. Comprehensive Inorganic Chemistry; 6, D. Van Nostrand Co., Inc.: Princeton, NJ, 1957; pp 204-221.

3. Timofeev, N .1.; Berseneva, F. N.; Makarov, V.M. New Palladium-Based Membrane Alloys for Separation of Gas Mixtures to Generate Ultrapure Hydrogen, "Int. J. Hydrogen Energy 1994, $19(1$ 1), 895-898.

4. Morooka, S.; Yan, S.; Yokoyama, S.; Kusakabe, K. "Palladium Membrane Formed in Macropores of Support Tube with Crossflow Through a Porous Wall, "Separation Science and Technology 1995, 30 (14), 2877-2889.

5. Koresh, J. E.; Soffer, A. "The Carbon Molecular Sieve Membranes: General Properties and the Permeability of $\mathrm{CH}_{4} / \mathrm{H}_{2}$ Mixtures, "Separation Science and Technology 1987, 22 (2, 3), 973-982. 
6. Mordkovitch, V.Z.; Baichtock, Yu. K.; Sosna, M.H. "The Large-Scale Production of Hydrogen from Gas Mixtures: A Use for Ultrathin Palladium Alloy Membrane Walls, " Int.J, Hydrogen Energy 1993, 18 (7), 539-544.

7 Inorganic Membranes Synthesis, Characterization, and Applications; Bhave, R. R., Ed.; Van Nostrand Reinhold: New York, 1991.

8. $\quad$ New Membrane Materials and Processes for Separation; Sirkar, K. K.; Lloyd, D. R., Eds.; American Institute of Chemical Engineers: New York, 1988; AIChe Symposium Series 261, Vol. 84, 1988.

9. Fain, D, E.; Roettger, G.E. "Coal Gas Cleaning and Purification with Inorganic Membranes," J. Engineering for Gas Turbines and Power 1993, 115, 628-633.

10. Egan, B. Z.; Fain, D. E.; Roettger, G. E.; White, D.E. "Separation Hydrogen from Coal Gasification Gases with Alumina Membranes," Journal of Engineering for Gas Turbines and Power 1992, 114, 367-370.

11. Ohya, H,; Hisamatsu, T,; Sate, S.; Negishi, Y. "Hydrogen Purification of Thermochemically Decomposed Gas Using Zirconia-Silica Composite Membrane, " 1994, 19 (6), 517-521.

12. Ohya, H.; Sate, S.; Ishii, A.; Negishi, Y.; Matsumto, K. "The Separation of Gaseous Mixtures with Composite Micropore Glass Membranes at High Temperature, "Int. J. Hydrogen Energy 1993, 18 (6), 475-479.

13. Ghate, M .R.; Jarr, L.A. Baker, Eds. Proceedings of the Sixth Annual Gasification Contractors Meeting; DOE/METC/-86/6043 (CONF-860649) (DE86006617).

14. Benedict, R. W.; Christensen, A. B,; Del Debbie, J .A.; Keller, J.II.; Knecht, D.A. "Technical and Economic Feasibility of Zeolite Encapsulation for Krypton-85 Storage," Exxon Nuclear Idaho Company, Inc., Report ENICO- 1011; Sept. 1979; 85p.

15. Fraenkel, D.; Shabtal, J. "Encapsulation of Hydrogen in Molecular Sieve Zeolites, "J. Am. Chem. Sot. 1977, 99, 7074-7076.

16. Fraenkel, D. "Encapsulate Hydrogen," Chemtech 1981, Jan., 60-65.

17. Fraenkel, D. "Zeolitic Encapsulation Part 1, Hydrogen Diffusion in A-Type Zeolite Encapsulates," J. Chem. Sot, Faraday Trans. 11981, 77, 2029-2033.

18. Fraenkel, D,; Ittah, B.; Levy, M. "The Behavior of Encapsulated Nonpolar Gases in Cs, NaA Zeolites Encapsulates," J. Chem. Sot., Faraday Trans. 11988, 84 (6), 1835-1885.

19. Fraenkel, D.; Levy, A. “Analysis of Temperature-Programmed Diffusion Chromatograms Obtained with Zeolite-Gas Systems," J. Chem. Sot., Faraday Trans. 11988, 84 (6), 1817-1834. 
20, Weitkamp, J.; Fritz, M.; Ernst, S. “Zeolites as Media for Hydrogen Storage, " Int. J. Hydrogen Energy 1995, 20 (12), 967-970.

21, Suzuki, H. "Composite Membrane Having a Surface Layer of an Ultrathin Film of CageShaped Zeolite and Processes for Production Thereof,' U.S. Patent 4699892, Oct. 13, 1987 ,

22, Blatter, F.; Schumacher, E. "ThePreparationo fPureZeoliteNaY and Its Conversionto High-Silica Faujasite," J. Chemical Education 1990,67(6),519-521.

23. Levy, F., Ed. intercalated Layered Materials; D. Reidel: Boston, 1979.

24, Foley, H.C. "Nonporous Carbons and Related Materials for Small Molecule Separations," Presented at the Symposium on Separations Using Inorganic Solids, Division of Petroleum Chemistry, 21 lth Annual Meeting American Chemical Society, New Orleans, LA, March 24-29, 1996; Abstracts, p 293.

25. Obolensky, M. A.; Chashka, K. B.; Beletski, V. I.; Basteev, A. V.; Solovey, V.V. "Hydrogen in Layer Structures, "Int. J, Hydrogen Energy 1993, 18 (3), 217-222.

26. Energy Research Corporation. "Novel Hydrogen Separation Device Development for Coal Gasification System Applications, " final report DOE/MC/26040-3529 (DE94000054).

27. Gur, T.; Belzner, A.; Huggins, R.A. "A New Class of Oxygen Selective Chemically Driven Nonporous Ceramic Membranes, Part I. A-Site Doped Perovskites," 1992, 75, 151--162.

28, Laidler, K.J. Chemical Kinetics; McGraw-Hill: New York, 2nd ed., 1965; pp 310-317.

29. Lin, C. L.; Wu, J. C. S.; Gallaher, G. R.; Smith, G. W.; Flowers, D. L.; Gerdes, T. E.; Liu P.K.T. "Gas Separations Using Ceramic Membranes," DOE/MC/25135-3341 (DE93000278), Feb. 1993; p 191,

30. Swanson, M .L. "Task 3.10- Gas Separation and Hot-Gas Cleanup," final topical report, 95EERC-08-02; Aug. 1995, p 15. 